\title{
Editorial
}

\section{Importance of Effective Leadership in Medical Institutes}

\author{
Abdul Sattar Memon, Iqbal Memon and N oshad Ahmed Shaikh
}

Leadership is just one of the many, but most important assets of any institute. New institutes and universities in last 5 to 7 years have been stepping forward to adapt new technologies and contemporary developments. Such patterns are also found in organization, those are specific for learning of subjects relevant to Medical and Health sciences. But this flexibility and adaptableness is with new gadgets and equipments that are not enough as it only shows focus on material gain for the accomplishment of personal 'make the most of attitude'. On the other hand success of a flourishing organization in real sense is that it must possess quality leaders. To do that care must be taken in distinguishing between the two concepts that are one showing success of expansions and extensions of physical entities; other is to provide strong leadership. Leadership is just one essential component of the directing role for that a leader also needs formal authority to be successful. "To be effectual or for any quality initiative to take hold, senior management must be involved and it must act as a role model and oversee continuous improvement of research and teaching". ${ }^{1}$ This involvement cannot be delegated, merely "because the main aim of a manager is to take full advantage of the resources available to maximize the productivity of the organization through administrative implementation". To accomplish this, managers must undertake the following function; planning, organizing, leading (delegating), controlling and for this senior management must realize, they have to provide adequate resources, passable empowerment and authority to relevant manager for him or her to put forth his authority through means of tough headship. The professional leadership of improvement must begin with a clear acknowledgement of the need for improvement. ${ }^{2}$ In some circumstances, leadership may not be required. For example, self motivated groups may not necessitate a solitary leader and may find "cream of the crop" dominating. The fact that a leader is not always required proves that leadership is just an asset and is not indispensable as long as organizations are successful and are able to carry out their objectives.

It is quite easy to defend the status quo than to change it, and in this difference lie the roots of the dominant professional response to the pressures on health care today ${ }^{3}$. Since, public sector organizations are lacking in quality and success as they miss quality people because of non-meritorious recruitment, or if they do find quality staff then they are deficient in experience or perhaps commitment due to underprovided environment of progress. Liaquat University of Medical \& Health Sciences, Jamshoro, has a potential and its personnel are brilliantly capable of accomplishing any given task as it shows their remarkable achievement to take lead to become first Public Sector University. Establishing degree awarding institute in public sector is not a story, but requires lot of throbbing, when you are up against so many odds and hard pressed probable issues.

\section{INVESTMENT IN PEOPLE}

Now, medical university workforce simply requires an investment in training to develop their present knowledge \& skills further. They require strong leadership to show them vision and smoothly sail them to accomplish the organizational objectives. One major investment area of leaders is to improve the overall functional capabilities of their subordinates i.e. to train them to particular relevance to their area of work.

Organizations striving for excellence and are determined to provide services of high-quality will understand that staff are crucial and decisive in the long run for the benefit and success of the organization, yet they are pricey resource to maintain and taken care of monetarily as well as they being vital component in organization resources. As faculty members are involved in core activities of teaching and research, magnitude of their importance shall be given added consideration. Although, training of employees who are nub of the company has been recognized as a central role of management since long. Importance and investment in the training of both central parts of personnel and support workforce are considered as a major influence on the success of the company.

To dig up optimized contribution from medical university employees, top hierarchy has to institute a vision, to comprehend it and accomplish the goals for which organization exists and on which organization's existence and creditability depends. To do so, it is necessary to chalk out positive strategies to invest in train- 
ing and guidance to sustain continuous workflow powerfully, professionally and proficiently.

\section{REFERENCES}

1. Bikmoradi A, Brommels M, Shoghli A, Sohrabi Z, Masiello I. Requirements for effective academic leadership in Iran: a nominal group technique ex- ercise. BMC Med Edu 2008; 8:24.

2. Berwick DM, Nolan TW. Physicians as leaders in improving health care: a new series in annals of internal medicine. Ann Int Med 1998; 128(4): 289-92.

3. Berwick DM. Medical associations: guilds or leaders? [Editorial] BMJ 1997; 314:1564-5.

AUTHOR AFFILIATION:

Prof. Abdul Sattar Memon

Dean Faculty of Surgery \& Allied Sciences

Liaquat University of Medical and Health Sciences

(LUMHS), Jamshoro, Sindh - Pakistan.

Mr. Iqbal Memon

Additional Controller of Examinations

LUMHS Jamshoro, Sindh - Pakistan.

Prof. Noshad Ahmed Shaikh

Professor of Surgery and Vice Chancellor

LUMHS Jamshoro, Sindh - Pakistan. 